\title{
Scoring System for Analyzing Vessel Development in Embryoid Bodies
}

\section{Timo Schinköthe ${ }^{1}$ and Annette Schmidt ${ }^{2}, 3 *$}

${ }^{1}$ Institute for Innovation and Medicine, Munich, Germany

${ }^{2}$ Bundeswehr Institute of Pharmacology and Toxicology, Munich, Germany

${ }^{3}$ Department of Molecular and Cellular Sport Medicine, German Sport University, Cologne, Germany

\begin{abstract}
Embryoid bodies (EB) derived from pluripotent embryonic stem cells (ES) are powerful tools for different purposes. One interesting aspect is vessel development and the use for simulating angiostatic effects of drugs. Unfortunately, it is difficult to compare the impacts of different drugs. Current methods allow the description of observations, but quantifying methods are missing.

To overcome that gap, we have developed a score system to transfer microscopic observations into quantifiable values. The score system summarizes different vessel characteristics within few categories and allows the comparison of drug effects in view of time and dosage. We analysed score behaviour with respect to normal vessel development as well as under presence of angiotstatic drugs. The vessel score showed a time-dependent increase under normal conditions while under presence of an angiogenesis-inhibitor the score increase was slowed, and under angiogenesis enhancing conditions the score increase was accelerated.
\end{abstract}

The presented vessel development score seems to be a helpful tool to transfer microscopic observations in EB vessel development into a quantifiable and comparable value.

Keywords: Embryoid bodies; Angiogenesis; Scoring; Vessel development

\section{Introduction}

Vascularization of organs and tissues is carried out by two related, but distinct processes: vasculogenesis and angiogenesis [1]. Vasculogenesis is a process where primitive blood vessels develop from angioblast precursor cells that differentiate and assemble into cord-like vascular structures which further connect into a primary network. Angiogenesis is a process of formation of new blood vessels from pre-existing vessels by sprouting, splitting, and remodelling of vascular network. It is a complex process including a chain of events like endothelial cell activation, growth, migration and capillary morphogenesis [2-5].

The process of angiogenesis requires the involvement of pro- and anti-angiogenic factors. Beside numerous biogenic factors, several modulators such as inhibitors, small molecules and monoclonal antibodies have been characterised that interfere with angiogenesis. Small molecules such as adenosine, 1-butyryl glycerol, prostaglandins $\mathrm{E} 1$ and $\mathrm{E} 2$ are a few examples also reported for their angiogenic activity [6-9]. Monoclonal antibodies such as bevacizumab and celecoxib and small molecules such as thalidomide are already used extensively in cancer therapy for their anti-angiogenic property [10-12].

Several in vivo and in vitro models were developed as an attempt to simulate the effects on angiogenesis. In vivo and in vitro experimental studies show that angiogenic inhibitors might act at different phases of angiogenic cascade such as migration, proliferation, differentiation and three-dimensional organisation of endothelial cells. One powerful tool to simulate angiogenic effects is the use of embryoid bodies (EBs). EBs are spheroidal three-dimensional embryonic tissues grown from pluripotent embryonic stem (ES) cells. They have been shown to differentiate into various cell types of all three germ layers and vessellike structures effectively improving the diffusion properties of the tissue. Because differentiation of ES cells has been known to recapitulate changes in the embryonic development, all progenic and angiogenic factors that hold essential functions during early embryogenesis are also expected to be involved in the formation of EBs [13].
Up to now microscopic interpretations of angiogenesis by using EBs were focussed on one or only few characteristics of endothelial development [14-16]. To improve the meaningfulness of microscopic observation of vessel maturation, a standardized interpretation method is required which allows the comparison of different experiments. The described scoring system is the first mathematical model which allows the analysis of vessel maturation in EBs in a time-dependent manner.

To prove the method we tested Tyrphastin 1296. Tyrphastin 1296 inhibits the autophosphorilation of PDGFß receptor (PDGFRß) which results in an inhibition of the PDGF pathway [17]. Endothelial sprouting, branching and pruning during angiogenesis depend on PDGFB/PDGFRß signalling [18].

\section{Material and Methods}

\section{Cell culture}

Mouse blastocyst-derived embryonic stem (ES) cells were established, maintained in culture and differentiated in vitro as described before $[19,20]$. For 2 days hanging drops were kept in 20 $\mu$ DMEM supplemented with $20 \%$ FCS. Subsequently, EBs were incubated for 3 days in suspension and plated in a 24-multiwell plate on gelatine-coated cover slips for 3, 6, 9 or 12 days in DMEM/15\% FCS. After that treatment cells were fixed with $4 \%$ paraformaldehyde in PBS for 25 minutes and washed with PBS [14].

*Corresponding author: Dr. Annette Schmidt, Ph.D, Department of Molecular and Cellular Sport Medicine, German Sport University, Cologne, Germany, Tel: +49899926922931; Fax: +49899926922333; E-mail: annette2schmidt@bundeswehr.org

Received November 30, 2015; Accepted January 28, 2016; Published January 31, 2016

Citation: Schinköthe T, Schmidt A (2016) Scoring System for Analyzing Vessel Development in Embryoid Bodies. J Stem Cell Res Ther 6: 325. doi:10.4172/21577633.1000325

Copyright: (c) 2016 Schinköthe T, et al. This is an open-access article distributed under the terms of the Creative Commons Attribution License, which permits unrestricted use, distribution, and reproduction in any medium, provided the original author and source are credited. 
Citation: Schinköthe T, Schmidt A (2016) Scoring System for Analyzing Vessel Development in Embryoid Bodies. J Stem Cell Res Ther 6: 325. doi:10.4172/2157-7633.1000325

Page 2 of 4

\section{Treatment of EBs}

EBs were treated with Testosterone or Tyrphostin 1296 for three days. The time point of adding testosterone was chosen in a way that EB fixation was on day three of incubation. EBs for control were kept untreated.

\section{Immunohistochemistry}

Cells were fixed as above and washed several times with $0.05 \mathrm{M}$ TBS and subjected to $0.25 \%$ Triton- $\mathrm{X} 100$ and $0.5 \mathrm{M} \mathrm{NH}_{4} \mathrm{Cl}$ in $0.05 \mathrm{M}$ TBS for cell membrane perforation. For blocking probes, 5\% BSA in TBS was used (1 hour, room temperature). To mark endothelial cells, the antibody rat anti-mouse-PECAM-1 (CD31) was used (1:800, mAb, Pharmingen, San Diego, CA, USA). The relevant secondary antibody was sheep anti-rat Ig biotinylated (1:400, Amersham, LIFE SCIENCE, Little Chalfont, Buckinghamshire, England). This biotinylated antibody was detected with Extravidin conjugated CY 3 (1:1000, Sigma Chemicals, St. Louis, MO, USA; absorption $552 \mathrm{~nm}$, emission $565 \mathrm{~nm}$ ).

\section{Statistical analysis}

All data are presented as mean SD. Data analysis was carried out using Student's test for unpaired data. Significance was considered at a $\mathrm{p}$ value $<0.05$.

\section{Results}

The aim of the developed score system was to achieve an objective method for quantifying vessel formation and ve sel maturation in embryoid bodies (EBs). Therefore microscopic o b servations were categorized into seven different properties. P roperties were subclassified as qualitative (three properties) and quantitative (four properties). Each single property has been a ssigned a score value. The single score values were then added up for the quantitative and qualitative properties respectively. Both achieved values were afterwards calculated as relative values in view of the achievable maximum (quantitative: 51 points; qualitative: 80 points). Both were then used as quantitative (Sqn) and qualitative score (Sql). The complete Score was derived as a product of both:

$$
\text { Score }=(S q n \bullet S q l)
$$

\section{Quantitative Microscopic Properties}

Three different chara cteristics were classified as quantit ative microscopic properties. These properties were length, thickness and the amount of vessels. In case the observed vessels were almost short instead of long, the length score achieved 1 point. In the opposite case (more long then short vessels) the score value with respect to length was 3 (Figure 1) (examples for short and long vessels are shown in Figure 1E and $1 \mathrm{~F}$ ). The same happened with the thickness of the vessels, the only difference being that higher score values were assigned (examples for thin and thick vessels are shown in Figure 1C and 1D). An intermediate group was defined for thickness and length. The amount of vessels was only classified as few or many (Table 1).

\section{Qualitative microscopic properties}

Qualitative pro perties are more difficult to objectify. Several microscopic obs ervations, that correlate to certain steps within the vessel maturation, were described based on their visual appearance (Figure 2). Shr edded vessels appear like short, cutted fragments of vessels (Figure 2C and 2D). If PECAM-positive cells were placed in a direct sequence and a short distance. i.e. one after the other, these were referred to as cobble-like (Figure 2E). If the PECAM-positive cell chains showed a plurality of links, this was referred to as network-like (Figure 2A and 2B).

\section{Median effect plot}

To describe the relationship between score and vascular development, we used a function analogous to the Hill plot for
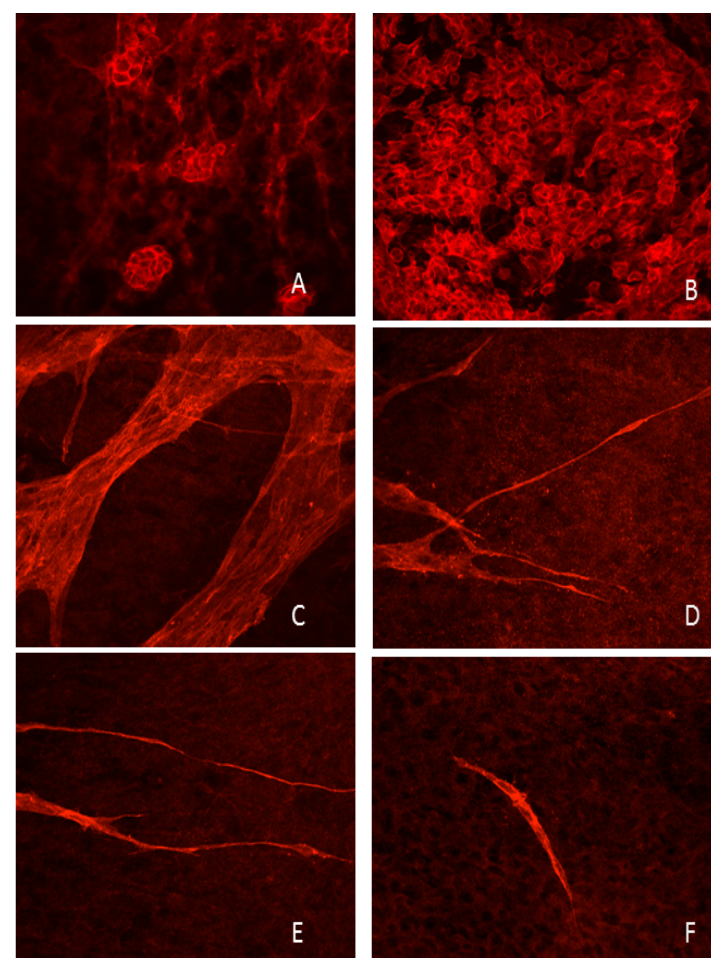

The first pictures illustrate angioblasts in a cluster $(A)$ or plain growing $(B)$. The other pictures illustrate vessels which are mostly thick (C), thin (D), long (E) or short (F). Scale bars: $5 \mu \mathrm{m}$.

Figure 1: Confocal microscopy pictures of PECAM stained EBs.

\begin{tabular}{|c|c|c|c|}
\hline \multicolumn{2}{|c|}{ Attributes } & Description & Score \\
\hline \multirow{8}{*}{ Vessel quantity } & \multirow{3}{*}{ Length } & $>70 \%$ short & 1 \\
\hline & & intermediate & 2 \\
\hline & & $>70 \%$ long & 3 \\
\hline & \multirow{3}{*}{ Thickness } & $>70 \%$ thin & 4 \\
\hline & & intermediate & 8 \\
\hline & & $>70 \%$ thick & 16 \\
\hline & \multirow{2}{*}{ Amount } & few & 16 \\
\hline & & many & 32 \\
\hline \multirow{12}{*}{ Vessel quality } & \multirow{3}{*}{ Shredded } & $<5 \%$ & 0 \\
\hline & & $5-30 \%$ & 1 \\
\hline & & $>30 \%$ & 2 \\
\hline & \multirow{3}{*}{ Cobble-like } & $<5 \%$ & 0 \\
\hline & & $5-30 \%$ & 3 \\
\hline & & $>30 \%$ & 6 \\
\hline & \multirow{3}{*}{ Network-like } & $<5 \%$ & 0 \\
\hline & & $5-30 \%$ & 9 \\
\hline & & $>30 \%$ & 18 \\
\hline & \multirow{3}{*}{ Mature vessels } & $<5 \%$ & 0 \\
\hline & & $5-30 \%$ & 27 \\
\hline & & $>30 \%$ & 54 \\
\hline
\end{tabular}

Table 1: Summary of all characteristics and corresponding values. 
Citation: Schinköthe T, Schmidt A (2016) Scoring System for Analyzing Vessel Development in Embryoid Bodies. J Stem Cell Res Ther 6: 325. doi:10.4172/2157-7633.1000325
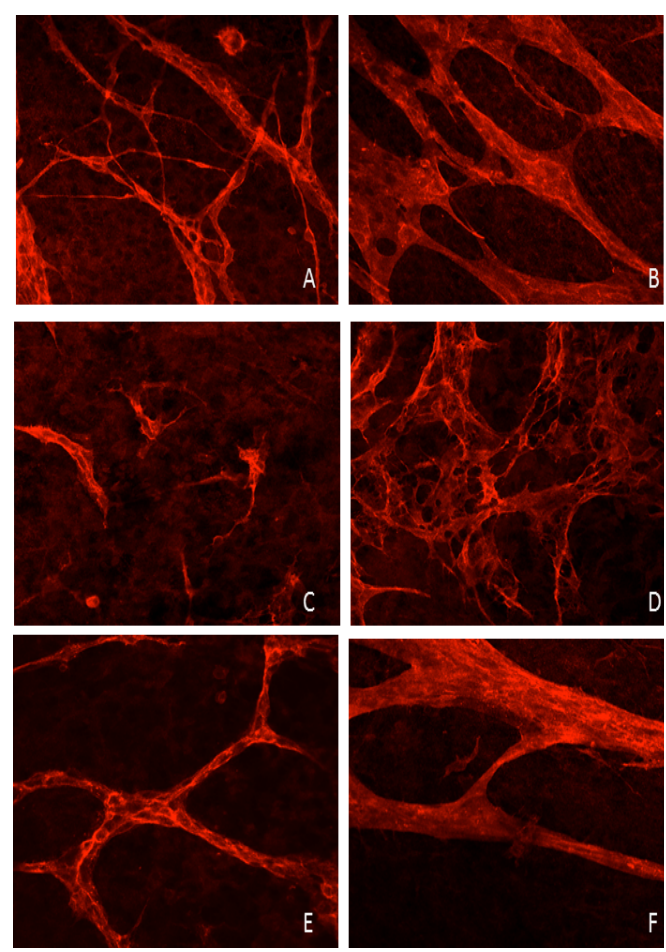

Picture $(A)$ and $(B)$ show network-like vessels whereas $(C)$ and $(D)$ illustrate shredded vessels. Picture $(E)$ is an example of cobble-like vessel and $(F)$ shows a mature vessel. Scale bars: $5 \mu \mathrm{m}$.

Figure 2: Confocal microscopy pictures of PECAM stained EBs.

cooperative systems. By using the median effect plot, which is defined as,

$$
\operatorname{Ln}\left(\frac{\text { Score }}{1-\text { Score }}\right)=a * \operatorname{Ln}(\text { age })+b
$$

the transition of the $\mathrm{x}$-axis shows the point of time, when the half maximum score is reached [21].

\section{Example}

In order to validate the efficiency and reliability of the scoring system, microscopic observations and mathematical transformations were carried out as mentioned earlier on normal EBs and on EBs incubated with testosterone. A normal EB yielded a half maximum time of 9.85 days. By incubating the EBs with testosterone, the speed of development was significantly increased. The EBs required only $65 \%$ of the time (6.36 days; $\mathrm{p}=0.049$ ) in comparison to normal EBs which substantiate the angiogenic activity of testosterone. In opposite treating EBs with the PEGF receptor inhibitor Tyrphastin 1296 increase the half maximum time by $50 \%$ to 14.9 days (Figure 3 ).

\section{Discussion}

Embryonic bodie s can be used to mimic developmental vasculogenesis and angiogenesis in vitro. But still current methods do only allow the description of microscopic observations but not statistical analysis. State-of-the-art publications still use descriptions of microscopic observations for the interpretation of drug effects [1416]. The presented scoring system might be useful to overcome that gap and to transfer microscopic observations of vessel development in embryonic bodies into statistical analyzable results. The easiest way to do, might be to use the median effect point of time. This time point is a single value which is closely related to vessel development. It is fast to calculate, directly comparable and can be used for statistical calculations.

The assay method developed on EB models for angiogenesis requires nothing more than a few critical observations of stained EBs made under confocal microscopy at different points of time which is feasible in any laboratory with basic infrastructure. Various parameters involved in angiogenesis such as the density of angioblasts, length, thickness and also the morphology of the endothelial cells are observed at different time periods. Therefore, this scoring method quantifies morphological parameters into values that are simplified into a score for easy interpretation.

Till date it was unknown that testosterone also has a generalized effect on the endothelium [22]. But through the current scoring method our results indicated that testosterone increased the vessel development. By analysing different parameters as it the case with the scoring model it showed that there is a significant effect on the speed of endothelial development. In only 6.4 days the endothelium reached the median effect point of time in comparison with the control EBs where the speed of development was significantly increased by $35 \%$.

Finally, such a methodology developed incorporating abundant information with respect to different time periods and also under influence of drugs would practically yield results that are very close to reality. Also, the ease of calculation and economical design would aid the portability of the proposed methodology to any clinical setting with only basic infrastructure. Given the above mentioned features, this scoring method can be applied as a potential tool in simulating side effects and assessing novel pro- and anti-angiogenic drugs in vascular therapy effectively. The other areas of interest could be in the area of developing designer steroids for assessing its angiogenic activity.

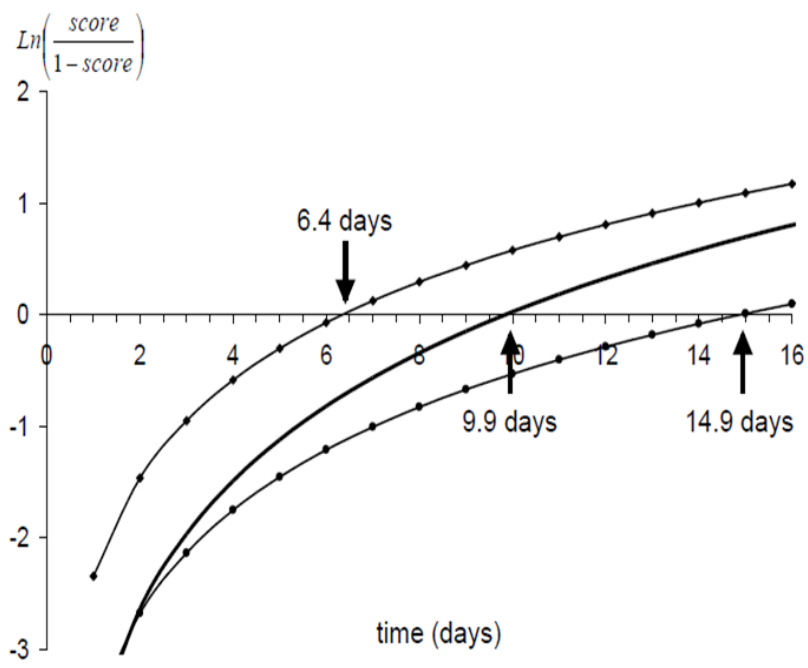

Normal EB reached a half maximum development score after 9.85 days whereas testosterone treated EBs only have a half maximum time of 6.35 days. EBs treated with Tyrphostin 1296 have a half maximum time of 14.9 days.

Figure 3: Example of vessel development of untreated EBs and treated with testosterone or Tyrphostin 1296. 
Citation: Schinköthe T, Schmidt A (2016) Scoring System for Analyzing Vessel Development in Embryoid Bodies. J Stem Cell Res Ther 6: 325. doi:10.4172/2157-7633.1000325

\section{Acknowledgement}

We thank Anika Voss for excellent technical assistance and Sabine van Hümmel for linguistic revision.

\section{References}

1. Risau W (1997) Mechanisms of angiogenesis. Nature 386: 671-674. [PubMed]

2. Flamme I, Frolich T, Risau W (1997) Molecular mechanisms of vasculogenesis and embryonic angiogenesis. J Cell Physiol 173: 206-210. [PubMed]

3. Asahara T, Murohara T, Sullivan A, Silver M, van der Zee R, et al. (1997) Isolation of putative progenitor endothelial cells for angiogenesis. Science 275 964-967. [PubMed]

4. Asahara T, Takahashi T, Masuda H, Kalka C, Chen D, et al. (1999) VEGF contributes to postnatal neovascularization by mobilizing bone marrow-derived endothelial progenitor cells. Embo J 18: 3964-3972. [PubMed]

5. Kalka C, Masuda H, Takahashi T, Kalka-Moll WM, Silver M, et al. (2000) Transplantation of ex vivo expanded endothelial progenitor cells for therapeutic neovascularization. Proc Natl Acad Sci U S A 97: 3422-3427. [PubMed]

6. Adair TH (2004) An emerging role for adenosine in angiogenesis. Hypertension 44: 618-620. [PubMed]

7. Dobson DE, Kambe A, Block E, Dion T, Lu H, et al. (1990) 1-Butyryl-glycerol: a novel angiogenesis factor secreted by differentiating adipocytes. Cell 61: 223230. [PubMed]

8. Mehrabi MR, Serbecic N, Tamaddon F, Kaun C, Huber K, et al. (2002) Clinical and experimental evidence of prostaglandin E1-induced angiogenesis in the myocardium of patients with ischemic heart disease. Cardiovasc Res 56: 214224. [PubMed]

9. Tamura K, Sakurai T, Kogo H (2006) Relationship between prostaglandin E2 and vascular endothelial growth factor (VEGF) in angiogenesis in human vascular endothelial cells. Vascul Pharmacol 44: 411-416. [PubMed]

10. Kramer I, Lipp HP (2007) Bevacizumab, a humanized anti-angiogenic monoclonal antibody for the treatment of colorectal cancer. J Clin Pharm The 32: 1-14. [PubMed]

11. Zhou Y, Ran J, Tang C, Wu J, Honghua L, et al. (2007) Effect of Celecoxib on E-cadherin, VEGF, Microvessel Density and Apoptosis in Gastric Cancer. Cancer Biol Ther 6: 269-275. [PubMed]

12. Teo SK (2005) Properties of thalidomide and its analogues: implications for anticancer therapy. Aaps J 7: E14-19. [PubMed]

13. Wartenberg M, Dönmez F, Budde P, Sauer H (2006) Embryonic stem cells: novel tool for the study of antiangiogenesis and tumor-induced angiogenesis. Handb Exp Pharmacol (174): 53-71. [PubMed]

14. Schmidt A, Wenzel D, Ferring I, Kazemi S, Sasaki T, et al. (2004) Influence of endostatin on embryonic vasculo- and angiogenesis. Dev Dyn 230: 468-480. [PubMed]

15. Piecewicz SM, Pandey A, Roy B, Xiang SH, Zetter BR, et al. (2012) Insulin-like growth factors promote vasculogenesis in embryonic stem cells. PLoS One 7: e32191. [PubMed]

16. Li J, Stuhlmann H (2012) In vitro imaging of angiogenesis using embryonic stem cell-derived endothelial cells. Stem Cells Dev 21: 331-342. [PubMed]

17. Lechuga CG, Hernández-Nazara ZH, Hernández E, Bustamante M, Desierto G, et al. (2006) PI3K is involved in PDGF-beta receptor upregulation postPDGF-BB treatment in mouse HSC. Am J Physiol Gastrointest Liver Physio 291: G1051-1061. [PubMed]

18. Hoch RV, Soriano P (2003) Roles of PDGF in animal development Development 130: 4769-4784. [PubMed]

19. Doetschman TC, Eistetter H, Katz M, Schmidt W, Kemler R (1985) The in vitro development of blastocyst-derived embryonic stem cell lines: formation of visceral yolk sac, blood islands and myocardium. J Embryol Exp Morphol 87: 27-45. [PubMed]

20. Fässler R, Rohwedel J, Maltsev V, Bloch W, Lentini S, et al. (1996) Differentiation and integrity of cardiac muscle cells are impaired in the absence of beta 1 integrin. J Cell Sci 109: 2989-2999. [PubMed]

21. Chou TC, Talalay P (1984) Quantitative analysis of dose-effect relationships: the combined effects of multiple drugs or enzyme inhibitors. Adv Enzyme Regul 22: 27-55. [PubMed]

22. Hwang GS, Wang SW, Tseng WM, Yu CH, Wang PS (2007) Effect of hypoxia on the release of vascular endothelial growth factor and testosterone in mouse TM3 Leydig cells. Am J Physiol Endocrinol Metab 292: E1763-E1769. [PubMed] 